\title{
The Analysis of the Perception on Planting Climbing Plants in Urban Community Gardens
}

\author{
Sang Mi Lee ${ }^{*}$, Young Chae, Young-Bin Jung, and In Kyoung Hong \\ Urban agriculture division, National Institute of Horticultural and Herbal Science, Rural Development Administration, Wanju 55365, Korea
}

\section{ABSTRACT}

This study is to find out the proper planting and utilization plans for climbing plants in urban community gardens. As a result, a majority of respondents claimed that it is acceptable to plant climbing plants in their plots of the community garden. In particular, those who have experiences with gardening activities responded that climbing plants could be allowed in the community gardens. There was a high tendency to use climbing plants in community gardens for aesthetic or ornamental use and for creating fences. Many respondents also claimed that the climbing plants should be planted outside or on the edge of the garden and that the plants should not cross over to other plots. Those who responded that the climbing plants should be planted outside or on the edge of the community garden wanted to use the plants for aesthetic or ornamental use. Those who wanted to use the plants for creating shades responded that the plants should be planted outside or on the edge of the garden. For proper planting of climbing plants in the community garden, it is necessary to consider the height of the vertical plant support depending to the gap between the plots in the community gardens, the shape and color of flowers, leaves, and stems for aesthetic use, and mixing of plants for the duration of the shade period. Accordingly, introduction of climbing plants can be considered to increase the diversity of plants in urban community gardens.

Keywords: diversity, fence, kitchen garden, shade, vines

\section{Introduction}

With the rapid urbanization, there is a growing interest in urban agriculture as a hobby and leisure activity for urban residents. Compared to 2010, the area of urban gardens in 2018 increased by 12.5 times from $1,040,000 \mathrm{~m}^{2}$ to $13,003,429 \mathrm{~m}^{2}$, and the number of participants in urban agriculture increased by 13.8 times from 153,000 to 2,121,685 (Ministry of Agriculture, Food and Rural Affairs, 2019). Such an increasing interest in urban agriculture and urban garden led to more studies and attempts in various fields such as types of urban agriculture (D.G. Lee, 2013), policies (Ji, 2011), operation and management (Chae, 2015), landscape and design of urban agricultural space (Oh, 2014; Kim, 2011), functions and effects (Jung, 2018). In partic- ular, gardening plants may vary depending on various factors such as the garden's location, season, purpose, and participants' knowledge about plants or preference, which is why they are a highly critical factor in seeking ways to develop gardens (Son, 2013). In Korea, kitchen gardens are perceived as a space of production, whereas in the West it is perceived as a space that provides a healthy life and rest, performing aesthetic, spiritual, environmental and therapeutic roles using plants (Kim, 2007). Recently there is also the term 'field garden' that refers to a multi-dimensional space with landscape function, not the primary space with the purpose of merely producing food (Chae, 2015; Hwang, 2018). The space in which residents can participate and build a community based on productive activities is also referred to as a community garden where there are

\footnotetext{
This study was supported by grants from the Rural Development Administration(PJ012607012019).

Received: November 5, 2019, Revised: November 19, 2019, Accepted: December 2, 2019

First author: Sang Mi Lee, sangmilee@korea.kr, (D) https://orcid.org/0000-0003-1049-4705

*Corresponding author: Sang Mi Lee, sangmilee@korea.kr, (D) https://orcid.org/0000-0003-1049-4705
} 
cultivation of crops, horticultural activities, education, play, leisure and rest, etc. (Park et al., 2011). A community garden is an open space created by the resident community (Kim, 2011) and can be used as a space of interaction among local residents in addition to leisure and rest, and must be a practical space that also performs aesthetic functions such as improvement of landscape and environment (Jeong et al., 2017). Accordingly, it must reflect the diversity of gardening plants in light of multiculturalism and multiple ethnicities (Agustina and Beilin, 2012). The Ministry of Agriculture, Food and Rural Affairs (2019) announced in the second five-year plan for urban agriculture that the aim will be shifted from the previous production-oriented urban agriculture to urban agriculture focused on culture-applied convergence service emphasizing the multiple values of urban agriculture. Nonetheless, urban garden plants reported in Korea are in the order of lettuce, cabbage, radish, and chili pepper ( $\mathrm{Yu}$ and Jang, 2002), chili pepper, lettuce, tomato, crown daisy, sesame leaves, cucumber, eggplant, and young radish (Choi et al., 2014), and lettuce, chili pepper, perilla, eggplant, and tomato (Son, 2013), which implies that plants are selected fragmentarily to use the leaves, stems, fruits and roots for food. In particular, urban community gardens that are shared and used by multiple people have the rule not to plant planting climbing plants to prevent plants from crossing over to neighboring gardens. However, climbing plants can be used as food ingredients or craft materials, and they express beautiful shapes in flowers, leaves and fruits as well as a sense of season such as abundance or a refreshing, cheerful and warm mood. The expression of lines from climbing stems also represent the fetal movement of life that begins from nature (Kim, 2014), which gives climbing plants value in terms of aesthetic and scenic use. However, climbing plants in urban agriculture are mostly planted on rooftops, outer walls of buildings or fences of houses to improve the urban environment (Shin, 2006; Xu et al., 2009; Yan and Zhou, 2008), and the types planted are red flower honeysuckle (Kim et al., 2007), Boston ivy (Kim and Kim, 2007; Lee, 2011; Lee and Kim, 2011), songak, fortunes creeping, and trumpet creeper (Kim et al., 2012; Lee et al., 2003), etc. Moreover, ivy, Japanese ivy, Asiatic jasmine, scindapsus, wax plant, etc. (Noh et al., 2010) are used for vertical greening to improve the indoor environment. In addition, climbing plants planted in urban gardens include pumpkin 33.1\%, cucumber 24.7\% (Pee, 2017), pumpkin $11 \%$, watermelon $4 \%$ (Kim, 2015), sponge gourd 3.3\%, and balsam apple 0.3\% (Lee, 2016). As examined above, introduction of climbing plants of urban agriculture is focused on indoor and outdoor artificial ground greening, and climbing plants in urban gardens are insufficient in terms of type and frequency.

Therefore, this study analyzes the perception on planting climbing plants in urban community gardens in terms of improving the diversity and multiple functions of urban community garden plants, seeks methods to adequately plant and utilize climbing plants in urban community gardens, and propose these methods to community garden participants and managers.

\section{Research Methods}

\section{Subjects and methods}

To publicly and randomly sample citizens interested in urban agriculture and agricultural technology, we selected the Busan Urban Agriculture Expo, Changwon Agricultural Technology Exhibition, and Hwaseong Urban Agriculture Expo as the target areas and conducted an on-site survey on 514 adults from April to November 2018. We used total 501 copies of the questionnaire as the final analysis data excluding the ones with insincere responses.

\section{Survey tool}

To determine the acceptability of implementing climbing plants in urban community gardens and the perception on suitable planting and utilization methods, the survey is comprised of items about the acceptability of planting climbing plants in the garden, considerations in planting, and uses of the plants. The acceptability of planting climbing plants in urban community gardens was provided in a single response item with options of '(1) acceptable (2) unacceptable (3) not sure'. For considerations when planting climbing plants in the gardens, the items were formed 
with reference to Gangdong-gu Office Farmers' Rules in the Garden (Cho, 2016), such as (1) the plants should not cross over to other plots (2) the plants should not shade other plots (3) the plants should be planted outside or on the edge of the community garden (4) the plants should be planted in the common space of the community garden (5) others, and multiple responses were possible. Moreover, for the preference for the use of climbing plants, the items were formed based on the leisure, rest, landscape and aesthetic functions of urban community gardens, such as (1) for edible or medicinal use (2) for aesthetic or ornamental use (3) for creating shades (4) for creating fences (space division) (5) for crafts (6) for others, and multiple responses were possible.

To analyze the relationship between perception on planting climbing plants and respondent characteristics, we examined gender, age, existence of a garden in residential space, and community gardening experience as respondent characteristics.

The results were analyzed with frequency analysis using SPSS Win 23.0, and non-response to certain items and items with multiple responses were reflected on the frequency. Furthermore, a cross-tabulation analysis is conducted to determine the relationship between perception on planting climbing plants and respondent characteristics as well as respondent age and gardening experience.

\section{Results and Discussion}

\section{Perception on the acceptability of planting climbing plants in urban community gardens}

For the question asking whether climbing plants can be planted in urban community gardens, more than half $(52.5 \%)$ of the respondents said it was acceptable, followed by not sure (24.2\%) and unacceptable (23.4\%; Table 1). However, this result is different from avoiding planting climbing plants such as pumpkins in urban gardens (Cho, 2016) because climbing plants cross over to the neighboring garden and cause conflicts and also cross over to the streets and cause inconvenience in mobility (H.J. Lee, 2013). There was no significant relation between the opin-
Table 1. Distribution of answers to the acceptability of planting climbing plants in urban community gardens

\begin{tabular}{ccc}
\hline Variable & Frequency $(\mathrm{N}=501)$ & $\%$ \\
\hline Acceptable & 263 & 52.5 \\
Not sure & 121 & 24.2 \\
Unacceptable & 117 & 23.4 \\
\hline
\end{tabular}

ions on the acceptability of planting climbing plants in urban community gardens and gender/existence of a garden in residential space, but there was a significant relation between age and gardening experience. The 20s responded that they are not sure, whereas all the others such as 30 s, $40 \mathrm{~s}, 50 \mathrm{~s}, 60 \mathrm{~s}$, and $70 \mathrm{~s}$ all said it is acceptable to plant climbing plants in gardens. In particular, the response that it is acceptable showed the highest ratio in the 50s (18.7\%) and 60s (11\%; Table 2). Moreover, the highest percentage $(27.2 \%)$ of those currently gardening responded that it is acceptable to plant climbing plants, followed by those who have gardening experience before (17.1\%). Meanwhile, those without gardening experience responded that they are not sure (13.3\%; Table 2). This is in line with the relation between age and gardening experience in Table 3, where most of the 20s responded that they do not have gardening experience at all, whereas many of the $30 \mathrm{~s}, 40 \mathrm{~s}, 50 \mathrm{~s}, 60 \mathrm{~s}$ and 70 s responded that they have gardening experience. In other words, the 20 s who have little gardening experience do not have clear opinions about the acceptability of planting climbing plants, whereas the $30 \mathrm{~s}, 40 \mathrm{~s}, 50 \mathrm{~s}, 60 \mathrm{~s}$ and $70 \mathrm{~s}$ with much gardening experience perceive that it is allowable to plant climbing plants in urban community gardens.

The results above are similar to the study proving that $76.1 \%$ of urban garden participants claimed that it is not difficult or manageable to try growing new crops (Kim, 2015). As shown in the results of this study, to resolve issues such as the demand for planting climbing plants by urban agriculture participants and the inconvenience due to climbing plants presented by garden management rules, it is necessary to establish relevant materials and provide education for participants to learn and practice management and utilization tips and cautions for planting climbing plants, helping them overcome the biggest difficulties they perceive, such as lack of gardening experience and skills (Kim, 2015). At the same time, it is necessary to establish 
Table 2. Relation between respondent's characteristics and opinions on the acceptability of planting climbing plants in urban community gardens

\begin{tabular}{|c|c|c|c|c|c|c|}
\hline \multirow{2}{*}{\multicolumn{2}{|c|}{ Independent variable }} & \multicolumn{3}{|c|}{ Dependent variable ${ }^{\mathrm{z}}$} & \multirow{2}{*}{$\chi^{2}$} & \multirow{2}{*}{$p$} \\
\hline & & Unacceptable & Acceptable & Not sure & & \\
\hline \multirow{2}{*}{ GE } & Male & $28(4.6)$ & $102(16.7)$ & $37(6.1)$ & \multirow{2}{*}{3.424} & \multirow{2}{*}{$.181^{\mathrm{NS}}$} \\
\hline & Female & $71(11.6)$ & 241(39.5) & $131(21.5)$ & & \\
\hline \multirow{6}{*}{$\mathrm{G}$} & $20 \mathrm{~s}$ & $18(3.1)$ & $38(6.2)$ & $31(5.1)$ & \multirow{6}{*}{22.541} & \multirow{6}{*}{$.013^{*}$} \\
\hline & $30 \mathrm{~s}$ & $14(2.3)$ & $48(7.9)$ & $30(4.9)$ & & \\
\hline & $40 \mathrm{~s}$ & $9(1.5)$ & $52(8.5)$ & $11(1.8)$ & & \\
\hline & $50 \mathrm{~s}$ & $30(4.9)$ & $114(18.7)$ & $52(8.5)$ & & \\
\hline & $60 \mathrm{~s}$ & $30(4.9)$ & $67(11.0)$ & $23(3.8)$ & & \\
\hline & 70 s or over & $9(1.5)$ & $22(3.6)$ & $11(1.8)$ & & \\
\hline \multirow{3}{*}{ EI } & Has & $42(8.3)$ & $120(23.6)$ & $45(8.9)$ & \multirow{3}{*}{4.325} & \multirow{3}{*}{$.364^{\mathrm{NS}}$} \\
\hline & Does not have & $40(7.9)$ & $177(34.8)$ & $75(14.8)$ & & \\
\hline & Not sure & $2(0.4)$ & $5(1.0)$ & $2(0.4)$ & & \\
\hline \multirow{4}{*}{ EP } & Participates & $45(7.5)$ & $164(27.2)$ & $41(6.8)$ & \multirow{4}{*}{43.934} & \multirow{4}{*}{$.000^{* * *}$} \\
\hline & Participated before & $24(4.0)$ & $103(17.1)$ & $43(7.1)$ & & \\
\hline & Does not participate & $27(4.5)$ & $74(12.3)$ & $80(13.3)$ & & \\
\hline & Others & $0(0.0)$ & $1(0.2)$ & $0(0.0)$ & & \\
\hline
\end{tabular}

Note. $\mathrm{GE}=$ gender; $\mathrm{AG}=$ age; $\mathrm{EI}=$ existence of a kitchen garden in residential space; $\mathrm{EP}=$ community gardening experience.

${ }^{\mathrm{z}}$ Value: frequency of Independent variable( $\%$ of Independent variable).

${ }^{\mathrm{NS}}$ Non-significant, ${ }^{*} p<.05,{ }^{* * *} p<.001$ by chi-square test.

Table 3. Relation between respondent's age and community gardening activity experience

\begin{tabular}{|c|c|c|c|c|c|c|c|}
\hline & \multirow{2}{*}{ Independent variable } & \multicolumn{4}{|c|}{ Dependent variable ${ }^{\mathrm{z}}$} & \multirow{2}{*}{$\chi^{2}$} & \multirow{2}{*}{$p$} \\
\hline & & Participates & Participated before & Does not participate & Others & & \\
\hline \multirow{6}{*}{ Age } & $20 \mathrm{~s}$ & $18(3.1)$ & $26(4.5)$ & $28(4.9)$ & $0(0)$ & \multirow{6}{*}{28.963} & \multirow{6}{*}{$.016^{* * *}$} \\
\hline & $30 \mathrm{~s}$ & $29(5.1)$ & $33(5.8)$ & $27(4.7)$ & $1(0.2)$ & & \\
\hline & $40 \mathrm{~s}$ & $34(5.9)$ & $16(2.8)$ & $20(3.5)$ & $0(0)$ & & \\
\hline & $50 \mathrm{~s}$ & $96(16.8)$ & $39(6.8)$ & $55(9.6)$ & $0(0)$ & & \\
\hline & $60 \mathrm{~s}$ & $49(8.6)$ & $33(5.8)$ & $29(5.1)$ & $0(0)$ & & \\
\hline & 70 s or over & $16(2.8)$ & $9(1.6)$ & $15(2.6)$ & $0(0)$ & & \\
\hline
\end{tabular}

${ }^{\mathrm{z}}$ Value: frequency of Independent variable( $\%$ of Independent variable)

${ }^{* * *} p<.001$ by chi-square test.

management plans such as rules and restrictions for participants when planting climbing plants in urban community gardens.

\section{Considerations when planting climbing plants in urban community gardens}

For considerations when planting climbing plants in urban community gardens, most participants (32.8\%) responded that they must consider that 'the plants should not ross over to other plots', followed by 'the plants should be planted outside or on the edge of the community garden'(28.0\%), 'the plants should not shade other plots' $(23.0 \%)$, and 'the plants should be planted in the common space of the community garden'(13.7\%; Table 4). As previously examined in the acceptability of planting climbing plants, it is necessary to resolve inconveniences such as climbing plants crossing over or shading other plots. Vertical gardening can be considered to avoid these issues, and 
height must be taken into consideration in this case. Ready-made vertical plant supports are around $50-200 \mathrm{~cm}$ long, and if the gap between gardens is small, the length of the support must be shortened to consider the extent and time of shading over other gardens. Out of 5516.5 $\mathrm{m}^{2}$ summer gardens in Gwangju, cucumbers were growing in $25.5 \%$ of them, pumpkins in $12.7 \%$, and gourds in $7.3 \%$. In $33.0 \mathrm{~m}^{2}$ summer gardens, cucumbers were growing in $58.2 \%$, pumpkins in 23.6\%, and gourds in 5.5\% (Son, 2013). This indicates that climbing plants are grown more in big gardens. Accordingly, to implement climbing plants in in- dividual gardens, it is necessary to secure at least a certain amount of space. However, if there is only a small gap between gardens or little individual planting space and thus inadequate for planting climbing plants, the climbing plants can be planted on the edges of the garden to use as a boundary for the garden.

There was no significant relation between opinions on considerations when planting climbing plants in urban community gardens and gender/age/existence of a garden in residential space/gardening experience (Table 5).

Table 4. Considerations for planting climbing plants in urban community gardens

\begin{tabular}{lcc}
\hline \multicolumn{1}{c}{ Variable } & Frequency $(\mathrm{n}=533)$ & $\%$ \\
\hline Plants should not cross over to other plots & 176 & 33.0 \\
Plants should be planted outside or on the edge of the community garden & 150 & 28.1 \\
Plants should not shade other plots & 122 & 22.9 \\
Plants should be planted in the common space of the community garden & 72 & 13.5 \\
Others & 13 & 2.4 \\
\hline
\end{tabular}

Table 5. Relation between respondent's characteristics and the considerations for planting climbing plants in urban community gardens

\begin{tabular}{|c|c|c|c|c|c|c|c|c|}
\hline \multirow{2}{*}{\multicolumn{2}{|c|}{ Independent variable }} & \multicolumn{5}{|c|}{ Dependent variable ${ }^{\mathrm{z}}$} & \multirow{2}{*}{$\chi^{2}$} & \multirow{2}{*}{$p$} \\
\hline & & \multirow{3}{*}{$\begin{array}{c}\mathrm{NC} \\
36(9.0) \\
105(26.2)\end{array}$} & \multirow{3}{*}{$\begin{array}{c}\mathrm{NS} \\
24(6.0) \\
57(14.2)\end{array}$} & \multirow{3}{*}{$\begin{array}{c}\mathrm{OE} \\
36(9.0) \\
75(18.7)\end{array}$} & \multirow{3}{*}{$\begin{array}{c}\text { CS } \\
19(4.7) \\
40(10.0)\end{array}$} & \multirow{3}{*}{$\begin{array}{l}\text { Others } \\
1(0.2) \\
8(2.0)\end{array}$} & & \\
\hline GF & Male & & & & & & 3171 & $530^{\mathrm{NS}}$ \\
\hline 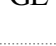 & Female & & & & & & 3.171 & \\
\hline \multirow{6}{*}{ AG } & $20 \mathrm{~s}$ & $19(4.8)$ & $12(3.0)$ & $12(3.0)$ & $2(0.5)$ & $0(0.0)$ & \multirow{6}{*}{22.481} & \multirow{6}{*}{$.315^{\mathrm{NS}}$} \\
\hline & $30 \mathrm{~s}$ & $20(5.0)$ & $14(3.5)$ & $15(3.8)$ & $10(2.5)$ & $2(0.5)$ & & \\
\hline & $40 \mathrm{~s}$ & $18(4.5)$ & $8(2.0)$ & $17(4.3)$ & $6(1.5)$ & $0(0.0)$ & & \\
\hline & $50 \mathrm{~s}$ & $39(9.8)$ & $22(5.5)$ & $44(11.0)$ & $20(5.0)$ & $2(0.5)$ & & \\
\hline & $60 \mathrm{~s}$ & $31(7.8)$ & $21(5.3)$ & $19(4.8)$ & $11(2.8)$ & $3(0.8)$ & & \\
\hline & 70 s or over & $12(3.0)$ & $6(1.5)$ & $3(0.8)$ & $6(1.5)$ & $1(0.3)$ & & \\
\hline \multirow{3}{*}{ EI } & Has & $50(14.7)$ & $25(7.3)$ & $41(12.0)$ & $25(7.3)$ & $5(1.5)$ & \multirow{3}{*}{11.850} & \multirow{3}{*}{$.158^{\mathrm{NS}}$} \\
\hline & Does not have & $70(20.5)$ & $41(12.0)$ & $50(14.7)$ & $25(7.3)$ & $3(0.9)$ & & \\
\hline & Not sure & $1(0.3)$ & $4(1.2)$ & $0(0.0)$ & $1(0.3)$ & $0(0.0)$ & & \\
\hline \multirow{4}{*}{ EP } & Participates & $61(15.4)$ & $30(7.6)$ & $50(12.6)$ & $25(6.3)$ & $1(0.3)$ & \multirow{4}{*}{8.454} & \multirow{4}{*}{$.749^{\mathrm{NS}}$} \\
\hline & Participated before & $40(10.1)$ & $25(6.3)$ & $33(8.3)$ & $13(3.3)$ & $4(1.0)$ & & \\
\hline & Does not participate & $40(10.1)$ & $24(6.0)$ & $28(7.1)$ & $18(4.5)$ & $4(1.0)$ & & \\
\hline & Others & $0(0.0)$ & $0(0.0)$ & $1(0.2)$ & $0(0.0)$ & $0(0.0)$ & & \\
\hline
\end{tabular}

Note. $\mathrm{GE}=$ gender; $\mathrm{AG}=$ age; $\mathrm{EI}=$ existence of a kitchen garden in residential space; $\mathrm{EP}=$ community gardening activity experience; $\mathrm{NC}=$ the plants should not cross over to other plots, $\mathrm{NS}=$ the plants should not shade other plots, $\mathrm{OE}=$ the plants should be planted outside or on the edge of the community garden, $\mathrm{CS}=$ the plants should be planted in the common space of the community garden.

${ }^{\mathrm{z}}$ Value: frequency of Independent variable(\% of Independent variable).

${ }^{\mathrm{NS}}$ Non-significant by chi-square test. 


\section{Plans to utilize climbing plants in urban community gardens}

Regarding how they want to use climbing plants in urban community gardens, most of them (26.4\%) preferred to use them for aesthetic or ornamental use, followed by for creating fences (space division; 24.9\%), for edible or medicinal use $(24.5 \%)$, for creating shades $(18.3 \%)$, and for crafts (5.1\%; Table 6). There is not a huge gap among the three ranks, but the result was different from various studies that the purpose of gardening is to produce safe chemical-free vegetables and healthy foods (Kim, 2015; Son, 2013; Youn, 2018). Moreover, it was different from the report by Son (2013) and Kim (2015) that most climbing plants in urban community gardens such as pumpkins, cucumbers, watermelons and Korean melons were edible. However, gardens must be approached from the perspective of using public space in the city and improving the urban environment, thereby maximizing various social and environmental values as well as quality of life (Lee, 2018). This is also consistent with the result that considering the aesthetic experience of urban agricultural landscape may be a foundation to display the positive functions of urban agriculture in creating a sustainable city (Shin, 2018). The results of this study suggest that the purpose and function of urban community gardens are become more diverse. Therefore, when choosing climbing plants to plant in urban community gardens, it is necessary to consider the aesthetic impression of the plants as well as ease of management so that they can be used not only for edible or medicinal use but also for ornamental use or space division. According to Son (2013), pumpkins and cucumbers planted in some urban community gardens had a relatively higher ratio of 'poor' or 'extremely poor' growth condition than other vegetables, which is due to the limitation of Cucurbitaceae vegetables with many plant lice and powdery mildew in the initial stage of growth (National Institute of Horticultural and Herbal Science, 2015). Here, it is suitable to use Cucurbitaceae plants such as sponge gourds with little disease and insect pest and longer vitality than other climbing plants (National Institute of Horticultural and Herbal Science, 2015), and pulse crops such as sword beans with little disease and insect pest, can be planted on extensive soil, and have white
Table 6. Preference for the use of climbing plants in urban community gardens

\begin{tabular}{ccc}
\hline Variable & Frequency $(\mathrm{n}=661)$ & $\%$ \\
\hline $\mathrm{A}$ & 174 & 26.3 \\
$\mathrm{~F}$ & 165 & 245.0 \\
$\mathrm{E}$ & 162 & 24.5 \\
$\mathrm{~S}$ & 122 & 18.3 \\
$\mathrm{C}$ & 34 & 5.1 \\
Others & 5 & 0.8 \\
\hline
\end{tabular}

Note. $\mathrm{A}=$ for aesthetic or ornamental use; $\mathrm{F}=$ for creating fences; $\mathrm{E}=$ for edible or medicinal use; $\mathrm{S}=$ for creating shades; $\mathrm{C}=$ for crafts.

flowers and straw cutter-shaped fruits for edible or ornamental use, and hyacinth beans with little disease and beautiful flowers and pods and thus are used for ornamental purpose or in salads (Rural Development Administration, 2018). Urban community garden users do not have much difficulty trying new crops (Kim, 2015), and thus by introducing and providing education on characteristics of each climbing plant as well as proper management and utilization methods, it would be possible to implement various climbing plants in urban community gardens. Moreover, it will be necessary to also use appropriate gardening structures or customized equipment to use climbing plants for creating fences or shades.

There was no significant relation between plans to utilize planting climbing plants in urban community gardens and gender/age/existence of a garden in residential space/gardening experience (Table 7).

\section{Relationship among subareas of perception on planting climbing plants in urban community gardens}

There was no significant relation between the acceptability of planting climbing plants in urban community gardens and considerations when planting climbing plants in gardens. However, there was a significant relation between the acceptability of planting and utilization plant, and between considerations and utilization plan. Among those who responded that climbing plants can be planted, most of them (17.3\%) responded they would plant them for edible or medicinal use, followed by for aesthetic or ornamental use (15.5\%), for creating fences (space division; 
Table 7. Relation between respondent's characteristics and preference for the use of climbing plants in urban community gardens

\begin{tabular}{|c|c|c|c|c|c|c|c|c|c|}
\hline \multirow{2}{*}{\multicolumn{2}{|c|}{ Independent variable }} & \multicolumn{6}{|c|}{ Dependent variable ${ }^{\mathrm{z}}$} & \multirow{2}{*}{$\chi^{2}$} & \multirow{2}{*}{$p$} \\
\hline & & \multirow{3}{*}{$\begin{array}{c}\mathrm{E} \\
36(7.0) \\
92(17.9)\end{array}$} & \multirow{3}{*}{$\begin{array}{c}\mathrm{A} \\
42(8.2) \\
95(18.4)\end{array}$} & \multirow{3}{*}{$\begin{array}{c}\mathrm{S} \\
30(5.8) \\
62(12.0)\end{array}$} & \multirow{3}{*}{$\begin{array}{c}F \\
22(4.3) \\
103(20.0)\end{array}$} & \multirow{3}{*}{$\begin{array}{c}\mathrm{C} \\
8(1.6) \\
21(4.1)\end{array}$} & \multirow{3}{*}{$\begin{array}{l}\text { Others } \\
0(0.0) \\
4(0.8)\end{array}$} & & \\
\hline & Male & & & & & & & & \\
\hline UL & Female & & & & & & & 9.005 & (0) \\
\hline \multirow{6}{*}{$\mathrm{AG}$} & $20 \mathrm{~s}$ & $12(2.3)$ & $16(3.1)$ & $22(4.3)$ & $24(4.7)$ & $4(0.8)$ & $0(0.0)$ & \multirow{6}{*}{29.461} & \multirow{6}{*}{$.245^{\mathrm{N}}$} \\
\hline & $30 \mathrm{~s}$ & $20(3.9)$ & 20(3.9) & $15(2.9)$ & $17(3.3)$ & $6(1.2)$ & $1(0.2)$ & & \\
\hline & $40 \mathrm{~s}$ & $13(2.5)$ & $21(4.1)$ & $11(2.1)$ & $17(3.3)$ & $1(0.2)$ & $0(0.0)$ & & \\
\hline & $50 \mathrm{~s}$ & $42(8.2)$ & $48(9.3)$ & $31(6.0)$ & $38(7.4)$ & $9(1.8)$ & $0(0.0)$ & & \\
\hline & $60 \mathrm{~s}$ & $31(6.6)$ & $20(3.9)$ & $14(2.7)$ & 20(3.9) & $5(1.0)$ & $3(0.6)$ & & \\
\hline & 70 s or over & $7(1.4)$ & $9(1.8)$ & $5(1.0)$ & $10(1.9)$ & $2(0.4)$ & $0(0.0)$ & & \\
\hline \multirow{3}{*}{ EI } & Has & $47(11.0)$ & $41(9.6)$ & $29(6.8)$ & $43(10.1)$ & $6(1.4)$ & $2(0.5)$ & \multirow{3}{*}{9.857} & \multirow{3}{*}{$.453^{\mathrm{NS}}$} \\
\hline & Does not have & $69(16.2)$ & $76(17.8)$ & $41(9.6)$ & $50(11.67$ & $15(3.5)$ & $1(0.2)$ & & \\
\hline & Not sure & $1(0.2)$ & $1(0.2)$ & $1(0.2)$ & $4(0.9)$ & $0(0.0)$ & $0(0.0)$ & & \\
\hline \multirow{4}{*}{ EP } & Participates & $65(12.8)$ & $58(11.5)$ & $36(7.1)$ & $48(9.5)$ & $12(2.4)$ & $0(0.0)$ & \multirow{4}{*}{16.6053} & \multirow{4}{*}{$.343^{\mathrm{NS}}$} \\
\hline & Participated before & $31(6.1)$ & $37(7.3)$ & $22(4.3)$ & $29(5.7)$ & $7(1.4)$ & $3(0.6)$ & & \\
\hline & Does not participate & $31(6.1)$ & $40(7.9)$ & $32(6.3)$ & $44(8.7)$ & $9(1.8)$ & $1(0.2)$ & & \\
\hline & Others & $0(0.0)$ & $0(0.0)$ & $1(0.2)$ & $0(0.0)$ & $0(0.0)$ & $0(0.0)$ & & \\
\hline
\end{tabular}

Note. $\mathrm{GE}=$ gender; $\mathrm{AG}=$ age; $\mathrm{EI}=$ existence of a kitchen garden in residential space; $\mathrm{EP}=$ community gardening activity experience; $\mathrm{E}=$ for edible or medicinal use; $A=$ for aesthetic or ornamental use; $S=$ for creating shades; $F=$ for creating fences; $C=$ for crafts.

${ }^{\mathrm{z}}$ Vales: Frequency of Independent variable(\% of Independent variable).

${ }^{\mathrm{NS}}$ Non-significant by chi-square test.

$11.5 \%)$, for creating shades $(10.3 \%)$, and for crafts $(3.0 \%)$. Moreover, most of the respondents who claimed that the plants should not cross over to other gardens responded that they would use the plants for edible or medicinal use (14.7\%) followed by for aesthetic or ornamental use (8.9\%). Among those choosing that the plants must be planted outside or on the edge of the garden, $7.9 \%$ responded that they would use the plants for aesthetic or ornamental use, and $7.7 \%$ for edible or medicinal use. Furthermore, most of the respondents claimed that the plants must be planted outside or on the edge of the garden to use them for creating shades (Table 8).

Urban community gardens, in which a limited land is divided consistently and shared by many people, had diverse areas of 1-50 $\mathrm{m}^{2}$, but most of them were 11-20 $\mathrm{m}^{2}$ (Lee, 2016), and many participants were expressing the need for a bigger area since their garden is too small (H.J. Lee, 2013). Planting climbing plants without a structure in a small garden makes it difficult to secure enough space to plant various plants. Thus, planting climbing plants on the edge of the garden will secure space for individual gardens and also create a fence for space division. Planting them in the common space of the garden will enable participants to enjoy them for ornamental use or relax in the shade. Plants with unique flowers and shapes of fruits or beautiful colors can be chosen for this ornamental purpose, and Cucurbitaceae plants with big leaves that grow quickly can be chosen for creating shades. However, even though Cucurbitaceae plants grow quickly, they tend to wither and dry up in September and October. Thus it is necessary to mix in some plants to maintain the shade until October and November.

\section{Conclusion}

This study is to seek proper planting and utilization plans for climbing plants that are avoided in urban community gardens to promote diversity and multiple functions of plants planted in urban community gardens, and it was con- 
Table 8. Relation between sub-domains of recognition about planting climbing habit plants in urban community gardens

\begin{tabular}{|c|c|c|c|c|c|c|c|c|c|c|}
\hline & \multirow{2}{*}{ Variable } & \multicolumn{6}{|c|}{$\mathrm{CD}^{\mathrm{z}}$} & \multirow{2}{*}{ Total } & \multirow{2}{*}{$\chi^{2}$} & \multirow{2}{*}{$p$} \\
\hline & & $\mathrm{NC}$ & \multicolumn{2}{|l|}{ NS } & $\mathrm{OE}$ & $\mathrm{CS}$ & Others & & & \\
\hline \multirow{4}{*}{ AP } & Unacceptable & $40(705)$ & \multicolumn{2}{|c|}{$24(4.5)$} & $20(3.8)$ & $9(1.7)$ & $2(0.4)$ & $95(17.8)$ & \multirow{4}{*}{11.544} & \multirow{4}{*}{$.173^{\mathrm{NS}}$} \\
\hline & Acceptable & $93(17.4)$ & \multirow{2}{*}{\multicolumn{2}{|c|}{$\begin{array}{l}72(13.5) \\
26(4.9)\end{array}$}} & $97(18.2)$ & $50(9.4)$ & $6(1.1)$ & $318(59.7)$ & & \\
\hline & Not sure & $43(8.1)$ & & \multicolumn{2}{|c|}{$33(6.2)$} & $13(2.4)$ & $5(0.9)$ & $120(22.5)$ & & \\
\hline & Total & $176(33.0)$ & $122(22.9)$ & \multicolumn{2}{|c|}{$150(28.1)$} & $72(13.5)$ & $13(2.4)$ & $538((100)$ & & \\
\hline & \multirow{2}{*}{ Variable } & \multicolumn{6}{|c|}{$\mathrm{PR}^{\mathrm{z}}$} & \multirow{2}{*}{ Total } & \multirow{2}{*}{$\chi^{2}$} & \multirow{2}{*}{$p$} \\
\hline & & $\mathrm{E}$ & A & $\mathrm{S}$ & $\mathrm{F}$ & $\mathrm{C}$ & Others & & & \\
\hline \multirow{6}{*}{$\mathrm{AP}$} & Unacceptable & $26(3.9)$ & $32(4.8)$ & $17(2.6)$ & $42(6.4)$ & $4(0.6)$ & $1(0.2)$ & $122(18.5)$ & \multirow{4}{*}{29.908} & \multirow{4}{*}{$.001^{* *}$} \\
\hline & Acceptable & $114(17.3)$ & $102(15.5)$ & $68(10.3)$ & $76(11.5)$ & $20(3.0)$ & $1(0.2)$ & $381(57.7)$ & & \\
\hline & Not sure & $22(3.3)$ & $40(6.1)$ & $35(5.3)$ & $47(7.1)$ & $10(1.5)$ & $3(0.5)$ & $157(23.8)$ & & \\
\hline & Total & $162(24.5)$ & $174(26.4)$ & $120(18.2)$ & $165(25.0)$ & $34(5.2)$ & $5(0.8)$ & $660(100)$ & & \\
\hline & \multirow{2}{*}{ Variable } & \multicolumn{6}{|c|}{$\mathrm{PR}^{\mathrm{z}}$} & \multirow{2}{*}{ Total } & \multirow{2}{*}{$\chi^{2}$} & $n$ \\
\hline & & $\mathrm{E}$ & A & $\mathrm{S}$ & $\mathrm{F}$ & $\mathrm{C}$ & Others & & & $p$ \\
\hline & $\mathrm{NC}$ & $71(14.7)$ & $43(8.9)$ & $21(4.4)$ & $33(6.8)$ & $1(0.2)$ & $1(0.2)$ & $170(35.3)$ & & \\
\hline & NS & $31(6.4)$ & $29(6.0)$ & $18(3.7)$ & $25(5.2)$ & $2(0.4)$ & $0(0.0)$ & $105(21.8)$ & & \\
\hline$C \mathrm{~S}_{\mathrm{S}}$ & $\mathrm{OE}$ & $37(7.7)$ & $38(7.9)$ & $24(5.0)$ & $31(6.4)$ & $6(1.2)$ & $0(0.0)$ & $136(28.2)$ & 156061 & $0 \cap \Omega^{* * *}$ \\
\hline $\mathrm{Cs}$ & $\mathrm{CS}$ & $11(2.3)$ & $24(5.0)$ & $15(3.1)$ & $6(1.2)$ & $3(0.6)$ & $0(0.0)$ & $59(12.2)$ & 150.001 & .000 \\
\hline & Others & $3(0.6)$ & $4(0.8)$ & $0(0.0)$ & $1(0.2)$ & $0(0.0)$ & $4(0.8)$ & $12(2.5)$ & & \\
\hline & Total & $153(31.7)$ & $138(28.6)$ & $78(16.2)$ & $96(19.9)$ & $12(2.5)$ & $5(1.0)$ & $482(100)$ & & \\
\hline
\end{tabular}

Note. $\mathrm{AP}=$ acceptability of planting climbing plants in urban community gardens; $\mathrm{CD}=$ considerations for planting climbing plants in urban community gardens; $\mathrm{PR}=$ preference for the use of climbing plants in urban community gardens; $\mathrm{NC}=$ the plants should not cross over to other plots; $\mathrm{NS}=$ the plants should not shade other plots; $\mathrm{OE}=$ the plants should be planted outside or on the edge of the community gardens; $\mathrm{CS}=$ the plants should be planted in the common space of the community gardens; $\mathrm{E}=$ for edible or medicinal use; $\mathrm{A}=$ for aesthetic or ornamental use; $\mathrm{S}=$ for creating shades; $\mathrm{F}=$ for creating fences, $\mathrm{C}=$ for crafts.

${ }^{\mathrm{z}}$ Values: Frequency of variable $(\%$ of variable).

${ }^{\mathrm{NS}}$ Non-significant, ${ }^{* *} p<.01,{ }^{* * *} p<.001$ by chi-square test.

ducted to determine the perception on climbing plants for gardens. The results showed that a majority of respondents claimed that it is acceptable to plant climbing plants in urban community gardens. Moreover, they tended to use climbing plants for aesthetic or ornamental use and for creating fences (space division). They preferred not to have the climbing plants cross over to other gardens when planting them, and preferred to plant them on the edge of the garden. Those who claimed that climbing plants can be planted outside or on the edge of the garden tended to more prefer using the climbing plants for aesthetic or ornamental use. Those who wanted to use the plants for aesthetic or ornamental use responded that the plants should not cross over to other gardens and can be planted outside or on the edge of the garden. Those who wanted to use the plants for creating shades responded that the plants can be planted outside or on the edge of the garden. The results above show that implementation of climbing plants can be actively considered to promote diversity of garden plants by taking account of the acceptability of planting climbing plants in urban community gardens, using gardening methods that consider the adequate situations and use, securing enough planting space in individual gardens, considering shapes and colors of flowers/leaves/stems for aesthetic or ornamental use, and mixing in other plants to maintain the shade longer. In particular, due to the limited space for individual planting in urban community gardens in this study, it is desirable to plant climbing plants with low ratio of plantation in the common space so that the planting design itself can be used as a space for rest or gathering. 
By using the aesthetic elements of planting design and plants for landscape, sharing the produced crops or using them for cultural activities such as farm parties, it would be possible to meet the needs for publicness, landscape, and comfort of urban community gardens. Furthermore, to induce constant participation of urban agriculture participants by arousing their interest and increasing their competency in plant cultivation, and meet various types, subjects and purposes of urban agriculture, it is necessary to seek diversity of plants to grow in the garden rather than to limit them, introduce different plants, and propose methods for adequate cultivation and use. However, this study has limitations in the survey items are few, fragmentary and tend to be general, thereby failing to closely analyze the relations among various factors. Therefore, it is necessary to conduct extended factorial research to explore and suggest adequate climbing plants to plant in urban community gardens based on the results of this study and follow-up research on plantation and field application.

\section{References}

Agustina I. and R. Beilin. 2012. Community gardens: Space for interactions and adaptations. Procedia Soc. Behav. Sci. 36:439-448. https://doi.org/10.1016/j.sbspro.2012.03.048

Chae, H.E. 2015. A study on the introduction and operation management for citizen participation vegetable-garden in urban agricultural public park. Master's thesis, Kongju National University, Gongju, Korea.

Cho, S. 2016, July 1. Farmers' rules in the vegetable garden [Gangdong urban agriculture portal]. Retrieved November 18, 2019, from https://www.gangdong.go.kr/cityfarm/w eb/18/progrm0403_view.do?pid=682

Choi, J.J., G.M. Gim, D.G. Park, J.H. Moon, S.M. Lee, S.J. Jeong, and A.K. Kim. 2014. Preference of crop species of allotment gardeners. Hortic. Sci. Technol. 32(Suppl. II):64.

Hwang, E.S. 2018. The effects of the vegetable gardening activity on young children's emotional intelligence and happiness. Master's thesis, Seoul National University of Education, Seoul, Korea.

Jeong, N.R., M.I. Jeong, S.W. Han, and J.S. Kim. 2017. Study on community gardens for village development projects. J. People Plants Environ. 20(1):7-17. https://doi.org/10.1 1628/ksppe.2017.20.1.007

Ji, T.G. 2011. A study on exploring an order of priority in urban agricultural policies: Using AHP analysis method. Doctoral dissertation, Paichai University, Dajeon, Korea.

Jung, D.C. 2018. A study on social function-based urban agriculture. Master's thesis, Chung-Ang University, Seoul, Korea.

Kim, E.J. 2014. A study on hair art design through the application of vine. Master's thesis, Daegu University, Gyeongbuk, Korea.

Kim, J.H. and I.S. Kim. 2007. Epidermal changes of the adhesive disks during wall attachment in Parthenocissus tricuspidata. Korean J. Electron Microsc. 37(2):83-91.

Kim, J.S., M.I. Jeong, S.W. Han, H.K. Jang, H.H. Jung, and S.M. Lee. 2012. Growth according to the direction of climbing wall and attachment characteristics of 5 vine plants on planting wall with various materials. J. Korean Soc. People Plants Environ. 15(6):471-475.

Kim J.Y., B.S. You, D.W. Lee, and Y.C. Kim. 2007. Covering screen of a roof garden used climbing plant Lonicera sempervirens. Proceedings of annual conference of Korean Society for Bio-Environment Control. 16(2):209.

Kim, M.H. 2011. Study on the community garden model utilizing a small vacant space in the urban area. Doctoral dissertation, Jeonnam National University, Gwangiu, Korea.

Kim, M.S. 2007. Preference analysis and plan on indoor kid's garden. Master's thesis, Dankook University, Chunan, Korea.

Kim, M.Y. 2015. Analysis for crop cultivation and its decisive factors in urban farming: Focusing on a Aynang and Gwacheon in Korea. Master's thesis, University of Seoul, Seoul, Korea.

Lee, B.G. 2016. A characteristics of kitchen garden of urban agriculture in Busan. Master's thesis, Kyungsung University, Busan, Korea.

Lee, D.G. 2013. A study of the preference on the type of urban agriculture, and activity preferences by lifestyle. Master's thesis, Hanyang University, Seoul, Korea.

Lee, H.J. 2013. Study on current situation of urban agri- 
culture focused on the farm of Suwon city. Master's thesis, University of Seoul, Seoul, Korea.

Lee, J.S., S.M. Ro, Y.S. Kim, and K.Y. Park. 2003. Growth, adhesive power, covering rate and ornamental value on vine plants in afforestation of the wall surface. Korean J. Hortic. Sci. Technol. 21(Suppl. I):222.

Lee, M.H. 2011. Characteristics of adhesive disks in Parthenocissus tricuspidata upon contact with various substrate surfaces. Master's thesis, Keimyung University, Seoul, Korea.

Lee, M.H. and I.S. Kim. 2011. Characteristics of adhesive disks in Parthenocissus tricuspidata during attachment. Korean J. Microsc. 41(2):139-145.

Lee, S.A. 2018. The influence of the characteristics of urban vegetable garden on satisfaction: Focusing on city of Ulsan. Master's thesis, Paichai University, Daejeon, Korea.

Ministry of Agriculture, Food and Rural Affairs. 2019. 2018 Urban agriculture status. Sejong, Korea: Author.

National Institute of Horticultural and Herbal Science. 2015. School gardening manual for teachers school garden A to Z. Wanju, Korea: Author.

Noh, J.M., Y.B. Lee, S.J. Lee, J.H. Seo, N.H. Yoon, H.Y. Son, S.J. Jeong, and W.S. Kim. 2010. Growth analysis of vine plants suitable for vertical gardening system at different indoor light condition. Korean J. Hortic. Sci. Technol. 28(Suppl II):118.

Oh, J.N. 2014. A plan about urban agriculture complex space for activation of local community. Master's thesis, Hong-Ik University, Seoul, Korea.

Park, E.J., Y.S. Lee, and C.H. Ahn. 2011. Characteristics of community garden based on social capital perspectives. J. Korea Inst. Ecol. Archit. Environ. 111(6):117-125.

Pee, O.J. 2017. Analysis of citizen vegetable garden and school farm activities in Sejong city. Doctoral dissertation, Chungbuk National University, Cheongju, Korea.

Rural Development Administration. 2018. Pulse cropsAgricultural technology guide 149. Wanju, Korea: Author.

Shin, M.J. 2018. Aesthetic experience of urban agricultural landscape. Master's thesis, Seoul National University, Seoul, Korea.

Shin, S.H. 2006. A study on the present status of domestic and foreign wall greening techniques and law system. Master's thesis, Seoul Women's University, Seoul, Korea.

Son, M.J. 2013. Investigation of crop growth as affected by area and season of urban vegetable garden. Master's thesis, Wonkwang University, Iksan, Korea.

Xu, R., H. Wang, and C. Gao. 2009. Application of parthenocissus to greening high-angle slope. Safety Environ. Eng. 16:35-37.

Yan, X. and L. Zhou. 2008. The feasibility of Parthenocissus tricuspidata introduction in the side slope vegetation restoration of Yinchuan Express Loop Highway. J. Shanxi Agric. Sci. 36:62-65.

Youn, E.S. 2018. A comparative study on the operation status and users' perceptions of urban garden fields. Master's thesis, Daegu Haany University, Kyoungsan, Korea.

Yu, C.J. and D.H. Jang. 2002. The analysis of the degree of cognition and satisfaction of city residents on weekend farms. J. Rural Soc. 12(1):63-88. 